
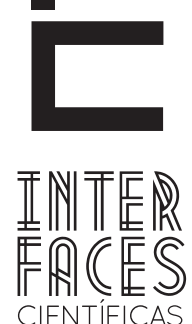

HUMANAS E SOCIAIS

ISSN IMPRESSO 2316-3348

E-ISSN 2316-3801

DOI - 10.17564/2316-3801.2016v5n2p43-52

\title{
TERRA, PROPRIEDADE E LUGAR: REFLEXÕES JURÍDICAS SOBRE 0 DESENVOLVIMENTO DE QUEBRADEIRAS DE COCO BABACU
}

LAND, PROPERTY AND PLACE: LEGAL CONSIDERATIONS ABOUT THE DEVELOPMENT OF BABASSU COCONUT BREAKERS

TIERRA, PROPIEDAD Y LUGAR: REFLECCIONES JURÍDICAS SOBRE EL DESARROLLO DE ROMPEDORAS DE COCO BABASÚ

Ciro de Souza Brito ${ }^{1}$

\section{RESUMO}

As quebradeiras de coco babaçu vêm se articulando nos últimos anos em busca da efetivação e garantia de direitos. Na Baixada Maranhense, Estado do Maranhão, vêm buscando um instrumento de regularização fundiária que possibilite o acesso aos recursos naturais para garantir a reprodução social do grupo. Neste sentido, este trabalho visa refletir, juridicamente, a respeito as diferentes concepções sobre a propriedade e sobre o acesso a terra, ambas relacionadas ao desenvolvimento das quebradeiras de coco babaçu. Para tanto, trazemos dados primários, coletados em trabalhos de campo desde 2014 , e dados secundários obtidos na literatura consulta- da. As reflexões sugerem que as quebradeiras têm direito ao desenvolvimento, privilegiando-se sua concepção de mundo e resguardando-se o seu lugar, enquanto categoria jurídica. Fica, ainda, a reflexão se o direito, tal como a agroecologia, pode ser ciência, movimento e prática.

\section{PALAVRAS-CHAVE}

Terra. Propriedade. Lugar. Quebradeiras de Coco Babaçu. Desenvolvimento. 


\section{ABSTRACT}

The Babassu coconut breakers come hinging in the last years searching fulfillment and guarantee of rights. At Baixada Maranhense, State of Maranhão, Brazil, they come seeking a regularization tool which enables access natural resources to ensure the social reproduction of the group. This paper aims to reflect legally different conceptions of property and of land access, both related to the development of Babassu coconut breakers. Therefore, we bring primary data collected in field work since 2014 and secondary data obtained in the literature. The reflections suggest Babassu coconut breakers has the right of development, privileging its conception of the world and protecting up its place as a legal category. It is also a reflection, such as in agroecology, if the law can be science, movement and practice.

\section{KEYWORDS}

Land. Property. Place. Babassu Coconut breakers. Development.

\section{RESUMEN}

Las rompedoras de coco babasú se están articulando, desde los últimos años, buscando la realización y garantía de derechos. En la Baixada Maranhense, Estado de Maranhão, Brazil, buscan una herramienta de regularización agraria, que permita el acceso a los recursos naturales para asegurar la reproducción social del grupo. Por lo tanto, este trabajo pretende reflexionar jurídicamente sobre las diferentes concepciones de la propiedad y el acceso a la tierra, ambas relacionadas con el desarrollo de las rompedoras de coco babasú. De hecho, traemos los datos primarios recogidos en el trabajo de campo desde 2014 y datos secundarios obtenidos en la literatura.
Las reflexiones sugieren que las rompedoras de coco babasú tienen el derecho al desarrollo, privilegiando su concepción del mundo y salvaguardando su lugar como una categoría legal. Además, se propone reflejar se el derecho, tal como la agroecología, puede ser ciencia, movimiento y práctica.

\section{PALABRAS-CLAVE}

Tierra. Propiedad. Lugar. Rompedoras de coco babasú. Desarrollo. 


\section{INTRODUÇ̄̃̃O}

A partir da realidade observada junto a quebradeiras de coco babaçu do Estado do Maranhão, este trabalho propõe uma reflexão acerca das diferentes concepções sobre o solo. Diferentes atores acionarão discursos, envolvendo terra e propriedade, enquanto apresentaremos a ideia de lugar e sua estreita vinculação com a concepção de desenvolvimento, principalmente por meio da regularização fundiária.

Essa concepção, enquanto construção conjunta referencia-se na agroecologia, enquanto ciência, movimento e prática transdisciplinar, que, por meio da pesquisa-ação visa a construção conjunta de conhecimento (científico e tradicional).

Nesse sentido, objetiva-se apresentar uma reflexão jurídica sobre o acesso a terra e sobre o direito ao desenvolvimento das quebradeiras de coco babaçu, tendo como parâmetro a regularização fundiária e, em segundo plano, como o direito pode colaborar nesse processo, seja como ciência, seja como movimento ou prática.

Os dados apresentados foram coletados em campo pelo grupo de pesquisa Conhecimento e Direito (CNPq) em períodos esparsos durante os anos de 2014, 2015 e 2016. A metodologia utilizada foi de pesquisa-ação, privilegiando-se observações diretas e participantes e entrevistas abertas e semiestruturadas. Somam-se, ainda, dados coletados na literatura.

\section{QUEBRADEIRAS DE COCO BABAÇU, IDENTIDADE COLETIVA E REIVINDICAÇÃO POR DIREITOS}

Ao longo dos últimos anos, o grupo de pesquisa Conhecimento e Direito (CNPq), do qual fazemos parte desde 2014, vem investigando ações que quebradeiras de coco babaçu, especialmente da região do Médio Mearim, Estado do Maranhão, realizam em prol da efetivação de direitos. Essas investigações partem da pesquisa-ação e demonstram, por exemplo, como a identidade das quebradeiras de coco babaçu vem se (re)construindo a partir da década de $80^{1}$ e como a tradição do grupo vem reforçando a sua ligação com a terra (VIEIRA-MARTINS, PORRO E SHIRAISHI NETO, 2014).

Por outro lado, vários atores vêm se opondo às práticas das quebradeiras. Essas oposições também têm sido fruto das investigações do grupo. É o caso do acesso ao conhecimento tradicional associado ao patrimônio genético do coco babaçu manejado pelas quebradeiras do Médio Mearim por parte da empresa Natura (PORRO; VEIGA, 2010; PORRO; SHIRAISHI NETO, 2012).

Atualmente, o grupo Conhecimento e Direito (CNPq) está investigando as relações recíprocas entre quebradeiras de coco babaçu, quilombolas e fazendeiros na região da Baixada Maranhense, no Estado do Maranhão, visando propor ao governo do Maranhão um instrumento de regularização fundiária para esses grupos conviventes.

Em que pese à questão fundiária sobressaia aos olhos, conforme demonstra Shiraishi Neto (2014a) em relação aos quilombolas, legítimas discussões teóricas giram em torno do denominado direito étnico². Contudo, como o próprio autor defende, o ordenamento jurídico brasileiro, graças ao princípio da isonomia, dá garantias equânimes a outros grupos tradicionais, razão pela qual não há que se diferenciar a situação dos quilombolas da situação das quebradeiras de coco babaçu.

1. Anny Linhares pesquisou sobre o tema, resultando em sua dissertação de mestrado defendida em março de 2016 no Programa de Pós-Graduação em Agriculturas Amazônicas do Núcleo de Ciências Agrárias e Desenvolvimento Rural, UFPA. Trabalho não publicado.

2. "O governo federal insiste em catalogar essas situações como se fossem problemas de ordem fundiária. 0 Decreto $n^{\circ} 4.887$, de 20 de novembro de 2003, que disciplina os procedimentos para a 'identificação, reconhecimento, delimitação, demarcação e titulação das terras', é fortemente marcado por esse viés. Ver também, o Decreto $\mathrm{n}^{\circ}$ 3.912, de 10 de setembro de 2001, que guarda conteúdo parecido" (SHIRAISHI NETO, 2014a, p. 3). 
Conforme observado em campo, o caso da Baixada Maranhense é emblemático pela convivência pacífica entre esses dois grupos tradicionais (quebradeiras de coco babaçu e quilombolas), tendo a especificidade de indivíduos que, inclusive, se autoidentificam como ambos.

Conforme apontam alguns estudos, essa "tradicionalidade" dos grupos emergentes se centra na identidade coletiva, principalmente vinculada a sua mobilização política. Isso tem corroborado as reivindicações por direitos coletivos de acesso a terra ${ }^{3}$.

Na literatura, vários autores apontam a problemática em torno do acesso a terra, enfrentada por camponeses no Brasil. É o caso de Maria Wanderley (2003) que revela que uma estratégia central para a reprodução dos grupos camponeses (e tradicionais, como o das quebradeiras e dos quilombolas) se dirige a constituição de patrimônio fundiário, uma vez que convivem em posses precárias da terra. Nesse sentido, a titulação de terras é um meio de garantia da reprodução social e física dos grupos tradicionais e essencial para o seu progresso e desenvolvimento (SHIARISHI NETO, 2014a).

Benatti (2003) e Mattos Neto (1988; 2010) desenvolveram teorias possessórias sobre a terra, visando a situação do camponês em relação ao caos fundiário brasileiro. Juristas, os autores apresentaram um rol de direitos que os camponeses, enquanto posseiros, teriam. Contudo, a posse, por ter um caráter precário, vem sendo reiteradamente desrespeitada por fazendeiros vizinhos de comunidades camponesas, prejudicando, portanto, a reprodução social desses grupos.

Este retrato se apresentou durante o campo realizado em 2014 no Médio Mearim. Segundo relatos de um representante do Sindicato dos Trabalhadores Rurais (STR) de Esperantinópolis, em maio de 2014, no povoado de São José, zona rural do município de

3. Sobre identidade coletiva, ver Roberto Cardoso de Oliveira (1976), Clerton Martins (2003) e Aldyr Balastreri Rodrigues (2014). E sobre mobilização política, ver Pantoja (2008), Almeida (2009) e Shiraishi Neto (2013; 2014a).
Esperantinópolis-MA, houve a pulverização de agrotóxicos, por meio de um avião da Globo Aviação Agrícola Ltda., em áreas de ocorrência de babaçu.

Os agrotóxicos utilizados, segundo laudo técnico realizado pela Associação em Áreas de Assentamento do Estado do Maranhão (ASSEMA), foram Dominum e Truper, ambos extremamente tóxicos e muito perigosos ao meio ambiente.

O laudo técnico da ASSEMA constatou que mais de 22 (vinte e duas) culturas foram afetadas pelos agrotóxicos (dentre elas: mandioca, fava, feijão, cuxá, quiabo, maxixe, abobora, pepino, melão, feijão guandu, banana, manga, maracujá, caju, jaca, graviola, acerola, goiaba, ata, laranja, coco e sapoti), além de três nascentes de água, um igarapé, treze poços e quatro açudes. Os danos gerados foram tanto visíveis quanto invisíveis.

Ocorre que essa pulverização, segundo informantes, de autoria de Simeão Carneiro Jovita (fazendeiro da região), foi para além dos domínios de sua propriedade e se alastrou por pequenas unidades familiares de produção, o que prejudicou a roça e o extrativismo realizado pelas famílias, uma vez que as plantações estariam morrendo devido o veneno aspergido.

O caso foi registrado na Delegacia de Polícia Civil de Esperantinópolis por meio do Boletim de Ocorrência n 313/2014-DPC/ESP/MA registrado por uma quebradeira de coco babaçu da região, que alegou que ela e outras quatorze pessoas teriam sido prejudicadas pela prática. A denunciante declara no Boletim de Ocorrência que ao procurar Simeão Jovita para contar o que estava acontecendo, ele teria se comprometido a visitar o local posteriormente, mas, de fato, não o teria feito.

O prejuízo se agravou, pois as famílias têm estreita ligação com a terra, nutrindo uma relação que extrapola fatores financeiros e se ligam a concepção de subsistência, de memória e de parentesco. 
A representante do STR de Esperantinópolis nos informou que no dia do ocorrido observaram que o avião da empresa Globo Aviação Agrícola Ltda. fazia voos rasantes sobre a propriedade, mas que a altura do avião parecia maior que a necessária para a pulverização de uma só propriedade. Este teria sido o fator responsável pelo envenenamento de outras áreas.

Ademais, os moradores da área afirmam que sabiam que o determinado avião não tinha licença ambiental para pulverizar a área. Tal fato foi divulgado em uma Nota de Utilidade Pública, assinada e divulgada por entidades como o STR de Esperantinópolis, a Cooperativa dos Pequenos Produtores Agroextrativistas de Esperantinópolis (COOPAESP) e outras entidades civis organizadas.

\begin{abstract}
Sabemos que veneno polui o ar, a terra, água, vegetação, animais, lençóis freático e o meio ambiente como um todo. E sendo colocado em altura entre 80 e 120 metros contamina em média de 10 a $12 \mathrm{Km}$. Ao redor do local da aplicação. Sendo assim a comunidade de Esperantinópolis está correndo o risco de sofrer maiores impactos de Saúde inalando agrotóxicos pulverizado em áreas vizinhas.

Esta pratica é proibida pelo IBAMA (Instituto Brasileiro de Meio Ambiente e dos Recursos Naturais Renováveis), exatamente pelo seu alto índice de contaminação ambiental, e são inúmeras os processos impetrados sobre tais praticas. E nós não iremos aceitar que essas práticas continue e volte a acontecer em nosso município. No entanto precisamos de apoio da população para que nos ajude a combater tal pratica! (TRECHO DA NOTA).
\end{abstract}

O caso acima retrata um conflito, envolvendo diferentes concepções sobre o uso dos recursos naturais. Por um lado, têm-se quebradeiras de coco babaçu, que, segundo informantes, são posseiras na região. E, de outro, tem-se a figura do fazendeiro responsável pela aspersão do veneno, segundo informantes, proprietário.

Entendemos que, sob o ponto de vista do fazendeiro, não há problemas na prática relatada, uma vez que, inclusive, a lei lhe confere direitos de uso, gozo e fruição de sua propriedade 4 . Contudo, sob o ponto de vista das quebradeiras de coco babaçu, tal ato prejudicou os recursos naturais por elas manejados e, por conseguinte, a própria reprodução social do grupo.

Apesar da situação prejudicial para as quebradeiras, enquanto posseiras, há casos diversos nos quais, atualmente, não são relatados problemas entre atores diferentes em uma mesma região. Podemos citar, ainda em relação à região do Médio Mearim, um trabalho que realizamos em Três Poços. Naquele momento, propomos a "relativização da propriedade", tendo em vista que não havia antagonistas aos posseiros da região, observando-se um estágio de convivência pacífico (MONTEIRO ET AL., 2015).

Ante as distintas situações que se apresentam, nosso foco se volta a Baixada Maranhense. Então, o que fazer e onde buscar respostas para viabilizar este instrumento de regularização fundiária de uma área em que convivem quebradeiras de coco babaçu, quilombolas e fazendeiros?

\section{LUGARE DESENVOLVIMENTO}

Como resposta aos questionamentos anteriores há algumas correntes teóricas. Alguns autores apontam como respostas a concretização de políticas públicas (SÁ; SILVA, 2014). Outros, diferentemente, apontam para o direito, seja por meio de criação de leis, seja por meio de uma diferente e arrojada interpretação dos dispositivos normativos já existentes (SHIRAISHI NETO, 2013; 2014a). Em relação ao direito, interessantes apontamentos fazem Antonio Carlos Wolkmer e Joquim Shiraishi Neto, acerca do chamado pluralismo jurídico.

Em síntese, Wolkmer (2012) constata que a teoria e a prática do direito moderno vêm continuamente sofrendo impacto da aglutinação de problemas es-

4. Conforme art. 1.228 do Código Civil de 2002. 
senciais e complexos, como as transformações nas condições de vida e a degradação ambiental. Em consequência, o clássico modelo jurídico-liberal-individualista tem sido pouco eficaz para recepcionar e instrumentalizar as novas demandas sociais, portadoras de "novos" direitos referentes a dimensões coletivas, por exemplo. Tal situação estimula e determina 0 esforço de propor novos instrumentos jurídicos mais flexíveis, mais ágeis, mais democráticos e mais abrangentes, capazes de regular situações complexas e fenômenos novos.

A seu turno, Shiraishi Neto (2014a) afirma que o direito não tem respondido de forma satisfatória às demandas oriundas dos grupos tradicionais, pois pretende adequar identidades étnicas mecanicamente às suas previsões (que se encontram distantes das situações de fato). "Assim, cabe ao direito, ancorado nas demais ciências e saberes, a interpretação dessa realidade social, isto é, proceder a um exercício hermenêutico de vinculação da Lei à realidade social e não o inverso" (SHIRAISHI NETO, 2014a, p. 7).

\begin{abstract}
No caso, tem-se um debate com a ciência jurídica tal como vem sendo oficialmente divulgada e ensinada, sendo que a construção da identidade revela um processo complexo próprio do pluralismo jurídico, que escapa do indivíduo e sublinha uma dimensão coletiva por fator étnico cada vez mais difícil de ser ignorada pela sociedade. Isso tudo indica a ausência de reflexão crítica do que seja o direito, de como ele funciona e da falta de coerência dos instrumentos jurídicos comumente utilizados. De fato, o direito tem se preocupado muito mais em adequar as demandas aos seus instrumentos, do que propriamente transformá-los. (SHIRAISHI NETO, 2014a, p. 12).
\end{abstract}

Logo, uma importante reflexão que se impende é: para onde vai o direito, especialmente no contexto pós-Constituição de 1988?

Para Shiraishi (2014a), o Estado Democrático de Direito deve ter o ser humano como seu núcleo central, conferindo ao ser humano, e consequentemente para toda a sociedade, o direito ao progresso. Aos gru- pos tradicionais também é conferido esse direito (ao progresso), que, para o autor, seria conferido por meio da titulação de terras, uma vez que elas garantiriam a reprodução física e social desses grupos e, desse modo, o progresso de cada um como ser humano.

Portanto, o direito ao progresso de grupos tradicionais seria o direito a sua reprodução física e social. Essa reprodução estreita-se à identidade coletiva desses grupos, que é composta por elementos culturais, sociais, econômicos e ambientais. Características estas vinculadas a terra em que os grupos estão locados, ao lugar.

Sobre o lugar, Shiraishi Neto (2014b) defende que seja tratado como uma categoria jurídica, uma vez que se extrai dos princípios da pluralidade e da isonomia, contidos na Constituição de 1988. 0 autor define lugar como "um espaço vivido e de pertencimento, articulado a uma rede de relações" (SHIRAISHI NETO, 2014b, p. 300).

Para o jurista, a noção de lugar é elemento-chave para a elaboração de qualquer proposta de desenvolvimento, pois abriga a diversidade dos grupos tradicionais.

Apesar de haver críticas sobre o discurso em torno de desenvolvimento, defendendo-se o chamado pósdesenvolvimento (ESCOBAR, 2010), parece cristalizado entre muitos pesquisadores que o desenvolvimento deve ser um objetivo da sociedade e, também, dos grupos tradicionais ${ }^{5}$. Inclusive, na Constituição brasileira, está presente a concepção de desenvolvimento sustentável, no artigo 225.

Elimar Nascimento (2012), ao traçar a trajetória da sustentabilidade, empresta a definição de Lenzi (2006) acerca de desenvolvimento sustentável como sendo "o desenvolvimento que satisfaz as necessidades do presente sem comprometer a capacidade das gerações fu-

5. Rui Mesquita Cordeiro (2014) traçou a trajetória dos projetos de desenvolvimento no Brasil, dando ênfase ao surgimento do debate ambientalista nos últimos anos. 
turas em satisfazer suas próprias necessidades” (LENZI, 2006 APUD NASCIMENTO, 2012, p. 54).

Nesse sentido, interessante os pontos levantados por Moreira e Carmo (2004), que dizem que a sustentabilidade está intimamente ligada aos processos de transformação da própria sociedade, devendo, portanto, passar por: 1) fortalecimento da agricultura de base familiar, 2) profundas modificações na estrutura fundiária do País, 3) políticas públicas consistentes e coerentes com a emancipação de milhões de brasileiros da miséria e 4) revisão dos pressupostos epistemológicos e metodológicos que guiam ações de pesquisa e desenvolvimento.

Mais uma vez a questão fundiária é apresentada e agora, reforçada como meio de alcançar o desenvolvimento sustentável. Aliado a esse ponto, tem-se a revisão dos pressupostos epistemológicos e metodológicos, que vem sendo objeto de investigação de pesquisadores de diversas áreas pelo mundo.

Vale destacar as contribuições de Boaventura de Sousa Santos, que desenvolveu a noção de epistemologias do sul. Para Santos (2012), trata-se de novos processos de produção e de valorização de conhecimentos (científicos e não científicos), a partir das práticas de grupos sociais emergentes. De fato, propõe-se a valorização de outros olhares, contra hegemônicos. Agroecologia, ciência que tem como principal referencial as epistemologias do sul e visa a construção conjunta entre conhecimento científico e conhecimento tradicional, é alternativa. Uma de suas proposições é a transdisciplinariedade desenvolvida por meio de pesquisa-ação (SEVILLA-GUZMÁN, 2013).

La técnica agroecológica central en estos casos es la investigación/acción participativa como mecanismo de ruptura de la relación científica sujeto-objeto. Esto implica, uma transformación radical en el sujeto científico; antes concebido como un observador neutral, objetivo y externo a la realidad que escruta y en la que el investigador no puedo intervenir. (SEVILLA-GUZMÁN, 2013, p. 105).
Em comum, tanto os discursos sobre desenvolvimento aqui elencados quanto os sobre pós-desenvolvimento têm o foco nas particularidades dos grupos emergentes, que reivindicam direitos específicos em prol de melhores condições de vida. Nesse sentido, a agroecologia apresenta-se como ciência, movimento e prática (WEZEL ET AL., 2009), cabendo nos questionarmos se a outras ciências também não caberia à mesma lição.

\section{CONCLUSÃO}

A guisa de conclusão, podemos afirmar que as quebradeiras de coco babaçu, enquanto grupo tradicional emergente, vêm reivindicando a garantia de direitos coletivos baseados na sua identidade, principalmente relativos ao acesso a terra. Antigos e novos instrumentos jurídicos vêm sendo pensados, em conjunto com o grupo, visando a efetivação de sua reprodução social, por meio da regularização fundiária.

De outro lado, há diferentes concepções sobre a terra, vinculadas ao conceito de propriedade, protegido pelo ordenamento jurídico brasileiro. Ante as dificuldades que se impõem, cabe pensar no direito ao desenvolvimento das quebradeiras, privilegiando a própria concepção de mundo que elas têm e resguardando o seu lugar, enquanto categoria jurídica.

Do lado da academia, o esforço é reflexivo e se encontra em definir estratégias conjuntas, principalmente no âmbito do direito, de como construir conhecimento, respeitando as particularidades dos grupos emergentes. Neste sentido, pergunta-se se o direito pode, tal como a agroecologia, ser ciência, movimento e prática.

\section{REFERÊNCIAS}

ALMEIDA, Alfredo Wagner Berno de. Biologismos, geografismos e dualismos:notas para uma leitura 
crítica de esquemas interpretativos da Amazônia que dominam a vida intelectual. In: PORRO, Roberto (Org.). Alternativa agroflorestal na Amazônia em transformação. Brasília: Embrapa, 2009.

\section{BENATTI, José Heder. Posse agroecológica e manejo florestal à luz da Lei no 9.985/2000. Curitiba: Juruá, 2003.}

CARDOSO DE OLIVEIRA, Roberto. Identidade, etnia e estrutural social. São Paulo: Livraria Pioneira, 1976.

CORDEIRO, Rui Mesquita. Os projetos de desenvolvimento do Brasil contemporâneo. Brazilian Journal of Political Economy, v.34, n.2, 2014. p.230-248.

ESCOBAR, Arturo. Una minga para el postdesarrollo: lugar, medio ambiente y movimentos sociales en las transformaciones globales. Lima: UNC, 2010.

MARTINS, Clerton. Identidade: percepção e contexto. In: MARTINS, J.C.O. (Org.). Turismo, cultura e identidade. São Paulo: Roca, 2003. p.39-48.

MATTOS NETO, Antonio José. A posse agrária e suas implicações jurídicas no Brasil. Belém: Cejup, 1988.

\section{MATTOS NETO, Antônio José. Estado de direito} agroambiental brasileiro. São Paulo: Saraiva, 2010.

MONTEIRO, Aianny; PORRO, Noemi; SHIRAISHI NETO, Joaquim; BRITO, Ciro. Conhecimento tradicional e propriedade privada entre quebradeiras de coco babaçu. Fragmentos de Cultura (On-line), v.25, n.2, 2015. p.275-285.

MOREIRA, Rodrigo Machado; CARMO, Maristela Simões do. Agroecologia na construção do desenvolvimento rural sustentável. Agric. v. 51, São Paulo, jul./dez. 2004. p.37-56.

NASCIMENTO, Elimar Pinheiro do. Trajetória da sustentabilidade: do ambiental ao social, do social ao econômico.Estudos Avançados, v.26, n.74, 2012. p.51-64.

PANTOJA, Mariana Ciavatta. Os Milton: cem anos de história nos seringais, com pós-escrito sobre os Kuntanawa. 2.ed. Rio Branco: EDUFAC, 2008. p.377-393.

PORRO, Noemi; SHIRAISHI NETO, Joaquim. Mais uma luta no campo jurídico: pelo conhecimento tradicional no modo de vida das quebradeiras de coco babaçu. Cadernos de Estudo. São Luís: editada pelos autores, 2012.

VEIGA, Iran. A experiência da COOPEAESP, ASSEMA E MIQCB com a Medida Provisória n².186-16 de 2001. Cadernos de Estudos. São Luís: MIQCB, 2010.

RODRIGUES, Aldyr Balasteri. Território, patrimônio e turismo com base local: uma relação inequívoca. In: SEABRA, Giovanni (Org.). Turismo de base local: identidade cultural e desenvolvimento regional. João Pessoa: UFPB, 2014.

SÁ, Tatiana Deane de Abreu; SILVA, Regina Oliveira da. Para além do interdisciplinar: a agroecologia como uma perspectiva transdisciplinar para a agricultura na Amazônia. In: VIEIRA, I.C.G.; TOLEDO, P.M.; SANTOS JR., R.A.O. (Org.). Ambiente e sociedade na Amazônia: uma abordagem interdisciplinar. V.1, Rio de Janeiro: Garamond, 2014. p.379-408.

\section{SANTOS, Boaventura de Sousa. 0 direito dos oprimidos. São Paulo: Cortez, 2014.}

SANTOS, Boaventura de Sousa. Introducción: las epistemologias del Sur. In: CIDOB (Org.). Formasotras: saber, nombrar, hacer. Barcelona: CIDOB, 2012. p.9-22.

SEVILLA-GUZMÁN, Eduardo. El despliegue de la Sociología Agraria hacia la Agroecología. Cuaderno Interdisciplinar de Desarrollo Sostenible (Cuides), n.10, abr. 2013. p.85-109. 
SHIRAISHI NETO, Joaquim. Os quilombos como novos "sujeitos de direito": processo de reconhecimento e impasses. Cadernos UNDB, v. 4, São Luís, jan-dez. $2014 a$.

SHIRAISHI NETO, Joaquim. Direito ao desenvolvimento: o lugar como categoria jurídica necessária a uma sociedade plural. Revista Jurídica da Presidência, v.16, n.109, Brasília, jun-set. 2014b. p.297-318.

SHIRAISHI NETO, Joaquim. 0 direito das minorias: passagem do invisível real ao visível formal? Manaus: UEA, 2013

VIEIRA-MARTINS, Pedro Sergio; PORRO, Noemi; SHIRAISHI NETO, Joaquim. O direito de propriedade ressignificado por quebradeiras de coco babaçu: a atualização da experiência no uso comum de recursos em uma comunidade tradicional. Revista da Faculdade de Direito da UFG, v.38, n.2, jul-dez. 2014. p.241-264.
WANDERLEY, Maria de Nazareth Baudel. Agricultura familiar e campesinato: rupturas e continuidade.

Estudos Sociedade e Agricultura, Rio de Janeiro, 21 out. 2003. p.42-61.

WEZEL, A. et al. Agroecology as a science, a movement and a practice: a review. Agronomy for sustainable development, v.29, dec. 2009. p.503-515.

WOLKMER, Antonio C., LEITE, José Rubens M. (Org.). Pluralismo, justiça e legitimidade dos novos direitos. Sequência (UFSC), n.54, jul-2007. p.95-106.

WOLKMER, Antonio C.; LEITE, José Rubens M. (Org.). Os "novos" direitos no Brasil:

natureza e perspectivas - uma visão básica das novas conflituosidades jurídicas./n:

WOLKMER, Antonio Carlos. Introdução aos fundamentos de uma teoria geral dos "novos" direitos. São Paulo: Saraiva, 2012. p.15-48. 
Recebido em: 1 de junho de 2016 Avaliado em: 14 de julho de 2016 Aceito em: 15 de julho de 2016
1. Advogado; Mestrando em Agriculturas Familiares e Desenvolvimento Sustentável; Programa de Pós-Graduação em Agriculturas Amazônicas, Núcleo de Ciências Agrárias e Desenvolvimento Rural, Universidade Federal do Pará. Bolsista CAPES. Membro do grupo de pesquisa Conhecimento e Direito (CNPq)

E-mail: ciro@ufpa.br 